\title{
Gene expression in human fungal pathogen Coccidioides immitis changes as arthroconidia differentiate into spherules and mature
}

Suganya Viriyakosol ${ }^{1 \dagger}$, Akul Singhania $^{2 \dagger}$, Joshua Fierer ${ }^{1,2,3}$, Jonathan Goldberg ${ }^{4}$, Theo N Kirkland ${ }^{1,2,3^{*}}$ and Christopher H Woelk ${ }^{1,2}$

\begin{abstract}
Background: Coccidioides immitis is a dimorphic fungus that causes disease in mammals, including human beings. It grows as a mycelium containing arthroconidia in the soil and in the host arthroconidia differentiates into a unique structure called a spherule. We used a custom open reading frame oligonucleotide microarray to compare the transcriptome of C. immitis mycelia with early (day 2) and late stage (day 8) spherules grown in vitro. All hybridizations were done in quadruplicate and stringent criteria were used to identify significantly differentially expressed genes.

Results: $22 \%$ of C. immitis genes were differentially expressed in either day 2 or day 8 spherules compared to mycelia, and about $12 \%$ of genes were differentially expressed comparing the two spherule time points. Oxireductases, including an extracellular superoxide dismutase, were upregulated in spherules and they may be important for defense against oxidative stress. Many signal transduction molecules, including pleckstrin domain proteins, protein kinases and transcription factors were downregulated in day 2 spherules. Several genes involved in sulfur metabolism were downregulated in day 8 spherules compared to day 2 spherules. Transcription of amylase and $a(1,3)$ glucan synthase was upregulated in spherules; these genes have been found to be important for differentiation to yeast in Histoplasma. There were two homologs of 4-hydroxyphenylpyruvate dioxygenase (4-HPPD); transcription of one was up- and the other downregulated. We tested the effect of a 4-HPPD inhibitor, nitisinone, on mycelial and spherule growth and found that it inhibited mycelial but not spherule growth.

Conclusions: Transcription of many genes was differentially expressed in the process of arthroconidia to spherule conversion and spherule maturation, as would be expected given the magnitude of the morphologic change. The transcription profile of early stage (day 2) spherules was different than late stage (day 8) endosporulating spherules. In addition, very few genes that are important for spore to yeast conversion in other dimorphic fungi are differentially expressed in C. immitis mycelia and spherules suggesting that dimorphic fungi may have evolved different mechanisms to differentiate from mycelia to tissue invasive forms.
\end{abstract}

Keywords: Coccidioides, Fungus, Spherules, Mycelia, Gene expression, Transcriptome

\footnotetext{
*Correspondence: tkirkland@ucsd.edu

${ }^{\dagger}$ Equal contributors

'Department of Medicine, University of California San Diego, La Jolla, CA

92093, USA

${ }^{2}$ Research Service, Veterans Affairs San Diego Healthcare System(111F), 3350

La Jolla Village Dr, San Diego, CA 92161, USA

Full list of author information is available at the end of the article
} 


\section{Background}

There are two closely related species of Coccidioides: immitis and posadasii that are found in different geographic areas [1]. They belong to the order Onygenales and are members of the phylum Ascomycota. Both Coccidioides species are indigenous to the New World where they grow as molds in the alkaline desert soils, primarily in North America, but also in scattered desert areas in South America [2]. These organisms are pathogenic for mammals (including humans), and it is estimated that there are 150,000 infections annually in the US, primarily in the southwestern region [3]. The soil form of these fungi is a mold that produces infectious spores (arthroconidia) that can become airborne if the soil is disturbed. Arthroconidia are $\sim 4$ micron in diameter and when inhaled into the lung they can cause pneumonia. Inside the host, under the influence of temperature and partial pressure of $\mathrm{CO}_{2}$, the organism undergoes a remarkable transformation into spherules, the pathognomonic tissue form of Coccidioides. Arthroconidia first round up and then they start to enlarge and transform. As they grow their cytoplasm undergoes internal segmentation to produce hundreds of endospores that are released when a spherule ruptures $[4,5]$. These endospores in turn enlarge into spherules and replication continues until the host immune response controls the process or the host dies. The two species of Coccidioides have the same life cycle and there is no known difference in the clinical disease caused by infection with the two species.

The natural history of coccidioidomycosis is very variable. About $60 \%$ of infections are mild and go undiagnosed, but in Arizona (a hyper-endemic region) coccidioidomycosis is a leading cause of symptomatic pneumonia [6]. Most of those infections resolve spontaneously but they can leave residual solitary granulomas or occasionally thin-walled cavities. In about $5 \%$ of cases infection does not remain confined to the lung and spreads to extrapulmonary sites. This spread can be an overwhelming, life threatening process, or it can manifest as isolated skin, bone, joint, or meningeal infections. The last is uniformly fatal without treatment. Most people with dissemination suffer from prolonged and debilitating infections that are difficult to treat [7]. People who are immunosuppressed, either by disease or iatrogenically, are at high risk for dissemination but the majority of disseminated cases occur in previously healthy individuals with no known immunological defects [8].

As with all the dimorphic pathogenic fungi (Blastomyces dermatitidis, Histoplasma capsulatum, Paracoccidioides brasiliensis and Sporothrix schenckii) the pathogenic form in tissue looks completely different form the saprobic mycelial form found in the environment. In coccidioidomycosis spherule formation is required for pathogenicity [9], as exemplified by two mutant strains $[10,11]$. Both of these mutants fail to form spherules and although mice can be infected, the infection resolves spontaneously.

One fundamental but poorly understood issue that is relevant to all the dimorphic pathogenic fungi is how they differentiate from a mold (i.e., arthroconidia in mycelia) to the pathogenic form (i.e., spherules). It is possible to induce spherule formation in vitro by incubating arthroconidia at an elevated temperature $\left(42^{\circ} \mathrm{C}\right)$ in a $14 \%$ $\mathrm{CO}_{2}$ atmosphere in a medium designed to promote the growth of spherules (Converse media) [12]. We chose to study gene expression in early spherules (day 2 in culture) that have not yet begun to form endospores and late spherules (day 8 in culture) that have formed endospores. The development of early and late spherules has been described $[4,5]$. C. immitis spherules do not rupture and release endospores when cultured in Converse media in our hands. We chose to compare gene expression in early and late spherules to mycelial gene expression to see whether gene expression varied as the spherules matured. We analyzed gene expression using a custom C. immitis oligonucleotide array platform constructed to probe the expression of every known and predicted open reading frame (ORF). Our hypothesis was that a large fraction of the genome would be differentially expressed in spherules compared to mycelia. We also hypothesized that many of the genes that are known to be important for mycelial to yeast conversion in other dimorphic pathogenic fungi would also be differentially expressed in the transition to spherules. Microarray gene expression analysis identified a large number of genes differentially expressed between the mycelial and spherule forms of the pathogen. The protein families (PFAM) and gene ontology (GO) terms significantly over-represented in the sets of differentially expressed genes were identified in order to better understand the higher biological processes being affected. Many genes associated with such families or terms were confirmed by real-time quantitative PCR (RT-qPCR). A study of C. immitis gene expression by Whiston et al. using RNA-Seq comparing transcript differences between mycelia and day 4 spherules was recently published and allowed us to compare our results to their results obtained at a time point intermediate in spherule development [13].

\section{Methods}

\section{Growth of mycelia and spherules}

C. immitis RS strain directly isolated from infected mice was grown on Mycosel agar (3.6\% Mycosel agar, 0.5\% yeast extract, and $50 \mu \mathrm{g} / \mathrm{ml}$ gentamicin). The animal protocol for infecting mice was approved by the Subcommittee on Animal Studies \#07-017. The plates were incubated at $30^{\circ} \mathrm{C}$ until the mycelia covered the surface of the agar. Arthroconidia were harvested from the plate 
after 6 weeks of incubation at $25^{\circ} \mathrm{C}$ by adding $25 \mathrm{ml}$ of saline. The plate was gently scraped using cell scraper and the fluid transferred to a $50 \mathrm{ml}$ tube that was then vigorously mixed for $10 \mathrm{sec}$ and centrifuged at $3000 \mathrm{rpm}$ for $10 \mathrm{~min}$ at $4^{\circ} \mathrm{C}$. The supernatant containing floating mycelia was discarded. The pellet containing arthroconidia was re-suspended in $10 \mathrm{ml}$ saline and the suspension was passed through a $40 \mu \mathrm{M}$ nylon cell strainer (BD Falcon). The strained suspension was centrifuged again and the pellet used to produce mycelia and spherules.

To grow mycelia, arthroconidia were washed 2 times with glucose-yeast extract (GYE) media and $2 \times 10^{6}$ spores/ $\mathrm{ml}$ were incubated in $250 \mathrm{ml}$ flat-bottom Erlenmeyer flasks (Corning) in $50 \mathrm{ml}$ GYE media. Four flasks were cultured in a $30^{\circ} \mathrm{C}$ incubator without shaking for 5 days. To grow spherules, arthroconidia were washed 2 times in modified Converse media [12]. The spores were inoculated at $4 \times 10^{6}$ arthroconidia $/ \mathrm{ml}$ into a $250 \mathrm{ml}$ baffled Erlenmeyer flask containing $50 \mathrm{ml}$ of modified Converse media. Eight identical flasks were set up and grown on a shaker at $160 \mathrm{rpm}$, in $14 \% \mathrm{CO}_{2}$ at $42^{\circ} \mathrm{C}$. Four flasks were harvested 2 days after inoculation and the remaining four flasks after 8 days. The spherules did not rupture and release endospores within that time in this culture system.

\section{Inhibition of growth with nitisinone}

Nitisinone, 2-(2-nitro-4-trifluoromethylbenzoyl)-cyclohexane-1, 3 dione, a potent specific inhibitor of 4-HPPD was purchased from Swedish Orphan Biovitrum, Sweden. A stock solution of $30 \mathrm{mg} / \mathrm{ml}$ was made in $0.2 \mathrm{M} \mathrm{NaOH}$. Nitisinone was added at several concentrations to glucose yeast extract media (GYE) or modified converse media in the presence of $2 \times 10^{6}$ spores $/ \mathrm{ml}$ in a $15 \mathrm{ml}$ round-bottom tissue culture tubes (BD Falcon). The culture was grown as described above for mycelial and spherule growth. The control tubes contained equal amounts of $0.2 \mathrm{M} \mathrm{NaOH}$ without Nitisinone. For microscopy, 1\% formaldehyde was added to the culture overnight and the tubes were centrifuged 10,000 rpm for $10 \mathrm{~min}$. The pellet was resuspended in Lactophenol Aniline blue stain (Remel) and examined microscopically.

\section{RNA isolation}

C. immitis mycelia were harvested by straining the media from four cultures through a $40 \mu \mathrm{M}$ nylon cell strainer (BD Falcon). The mycelia were picked up from the cell strainer using a sterile disposable loop (BD Falcon) and dropped in a $2 \mathrm{ml}$ ZR BashingBead lysis tube with $0.5 \mathrm{~mm}$ beads (Zymoresearch) and $0.5 \mathrm{ml}$ Qiazol reagent (Qiagen). The tubes were arranged in a pre-cooled Tissuelyzer II adapter (Qiagen) and mycelia was disrupted by shaking at $50 \mathrm{~Hz}$ for $25 \mathrm{~min}$. Spherules in Converse media were harvested from four 2 day cultures and four 8 day cultures. The cell concentration was determined by counting the spherules in Lactophenol Aniline blue stain. The media was centrifuged at 10,000 $\mathrm{rpm}$ for $10 \mathrm{~min}$ at $4^{\circ} \mathrm{C}$. Qiazol (Qiagen) was added to the cell pellet at $4 \times 10^{6}$ spherules $/ \mathrm{ml}$ and $0.5 \mathrm{ml}$ of the mixture added to a $2 \mathrm{ml}$ ZR BashingBead lysis tube with $0.5 \mathrm{~mm}$ beads (Zymoresearch). Total RNA was purified from mycelia and spherule samples (4 replicates/condition) using the RNeasy Microarray tissue mini-kit (Qiagen) in a Qiacube machine (Qiagen). If necessary RNA was concentrated or re-purified using RNeasy Minelute Cleanup kit (Qiagen) according to the manufacturer's protocol. Total RNA concentrations were initially determined using a NanoDrop spectrophotometer (NanoDrop) and RNA quality was assessed using a 2100 Bioanalyzer (Agilent). All samples had a RNA integrity number greater than 7 .

\section{Microarray design and hybridization}

Known and predicted ORFs from the C. immitis genome (RS strain) were previously identified using sequence data available at the Broad Institute [14]. This information was supplied to Roche Nimblegen in order to manufacture a custom oligonucleotide array consisting of 68,927 probes (Nimblegen custom array OID30589). Probes were 60 nucleotides in length and the expression of the majority of genes was assayed using 7 different probes printed in duplicate. The expression of small genes was assayed with fewer probes. Twelve custom microarrays fit on a single slide such that all the samples in this study $(4 \times$ mycelia, $4 \times$ day 2 spherule, and $4 \times$ day 8 spherule) could be assayed for gene expression in a single experiment to eliminate technical batch effects. Ten $\mu \mathrm{g}$ of total RNA at a concentration greater than 1 $\mu \mathrm{g} / \mathrm{ml}$ from each sample was used for microarray hybridization. Total RNA was converted to cDNA, labeled with dye, and hybridized to the microarray by the VA San Diego Gene Chip Microarray Core according to the Nimblegen protocol. All C. immitis genes are referred to by their locus tag and further information about these genes can be found at the Coccidioides group database at the Broad Institute http:/www.broadinstitute.org/annotation/ genome/coccidioides_group/MultiHome.html. FungiDB (http://fungidb.org/fungidb/) was also used for annotation because it has more informative gene names for many genes.

\section{Microarray data analysis}

Quality control analysis and normalization of microarray gene expression data were performed as previously described [15]. Briefly, several quality control assessments (e.g., boxplots and volcano plots) were applied to assess microarray data quality. Unsupervised clustering was also performed using the web-based tool ANAIS [16] to determine if samples clustered as expected based on the 
expression of genes in each sample. All arrays passed quality control filters and no outliers were found. Differentially expressed probes were identified between mycelium, day 2 spherule and day 8 spherule conditions using a one-way ANOVA and the Tukey post hoc test implemented in GeneSpring GX version 11.5 (Agilent Technologies Inc.). The false discovery rate (FDR) associated with multiple tests was corrected for using the Benjamini-Hochberg method [17]. In a conservative approach, a gene was only identified as differentially expressed if all probes for that gene had a fold change greater than 2 or less than -2 and an ANOVA $p$-value (Tukey and FDR corrected) less than 0.05. Fold changes were calculated for each gene that passed this filter by averaging across the seven probes. The overlap in up and downregulated genes between day 2 and day 8 spherules compared to mycelia was visualized in Venn diagrams using BxToolBox (http://bioinforx.com/). The ANOVA analysis was also used to identify genes that were differentially expressed between day 2 and day 8 spherules where positive fold changes are indicative of greater expression at day 8 compared to day 2 and negative fold changes suggest decreased expression. Gene expression data are available at the Gene Expression Omnibus (http://www.ncbi.nlm.nih.gov/geo/) under accession number GSE44225.

\section{PFAM and GO analysis}

PFAM enrichment was determined using a tool at the Broad Institute http://www.broadinstitute.org/ annotation/genome/coccidioides_group/BatchSelect. html?target=GeneEnrichment.html. This tool looks for over-representation of PFAMs in up- or downregulated genes using a hypergeometric test, and only PFAMs with an FDR-corrected $\mathrm{p}$-value $<0.05$ were considered significant.

GO terms were assigned to C. immitis genes by reciprocal homology searches at the protein level against the Saccharomyces cerevisiae proteome using BLAST (Additional file 1: Table S1). UniProt IDs were obtained using the $C$. posadasii homologs of $C$. immitis genes because many more $C$. posadasii genes have UniProt IDs. The Biological Networks Gene Ontology (BiNGO) plugin (version 2.441) [18] for Cytoscape (version 2.8.3) was used to identify those GO terms related to biological processes that were over-represented for differentially expressed genes identified between each of the three comparison groups (mycelia vs. day 2 spherule, mycelia vs. day 8 spherule, day 8 vs. day 2 spherule). BiNGO preserves the hierarchical relationship between GO terms. Significance was assessed with a hypergeometric test and only GO terms with an FDR-corrected p-value $<0.05$ were considered significant.

\section{Gene annotation}

C. immitis protein kinases were identified and classified by orthology with the curated Trichophyton rubrum kinome [19]. Non-orthologous kinases were identified and classified by searching the proteome with a protein kinase HMM built from an alignment of Dictyostelium kinases [20] followed by a BLAST against the curated kinase database (http://kinase.com/) [21]. Kinase abbreviations are provided in Additional file 2: Table S3. Signal peptides in the proteins coded for in the C. immitis genome were identified using artificial neural networks implemented in SignalP version 4.0 [22].

\section{RT-qPCR confirmation of gene expression}

Microarray gene expression was confirmed by RT-qPCR for 24 genes. Three highly expressed genes with low standard deviation across the 12 samples were selected as normalizers (CIMG_01599, CIMG_10083 and CIMG_12902). $\mathrm{SYBR}^{\circ}$ Green primers were designed using Primer Express version 3.0 (Applied Biosystems Inc.) and obtained from Integrated DNA Technologies, Inc. (Coralville, IA). Reverse primers were designed to span a splice site in the same region of the gene probed by the microarray. Duplicate RT-qPCR reactions were performed for each sample using $50 \mathrm{ng}$ of reverse transcribed RNA per reaction. Fold changes were calculated as described previously using the $2^{-\Delta \Delta C T}$ method [23] implemented in the DataAssist software version $3.0(\mathrm{ABI})$, and significance was determined using one-way ANOVA in the R statistical package (version 2.13.2).

\section{Results and discussion}

\section{Genes differentially expressed in mycelia and spherules}

Gene expression was assessed in a total of 12 samples derived from 4 replicate samples isolated from the following three growth phases: mycelia, day 2 spherules, and day 8 spherules. A photograph of mycelia and day 2 and day 8 spherules grown in Converse medium is shown in Figure 1. The image shows the difference in shape and size between spherules and mycelia and the increase in spherule size between 2 and 8 days of culture. A custom oligonucleotide microarray (Nimblegen), which contained probes for all predicted ORFs of the RS strain of $C$. immitis was used to assess gene expression. 91\% of the predicted ORFs were expressed in either mycelia or spherules, suggesting that the annotation and the detection of hybridization were robust. Unsupervised clustering using the expression of all genes on the microarray revealed that mycelia samples clustered distinctly from spherule samples. Furthermore, spherule samples formed two sub-clusters based on the number of days in culture. A dendrogram showing that the four replicate samples cluster together is shown in Additional file 3: 


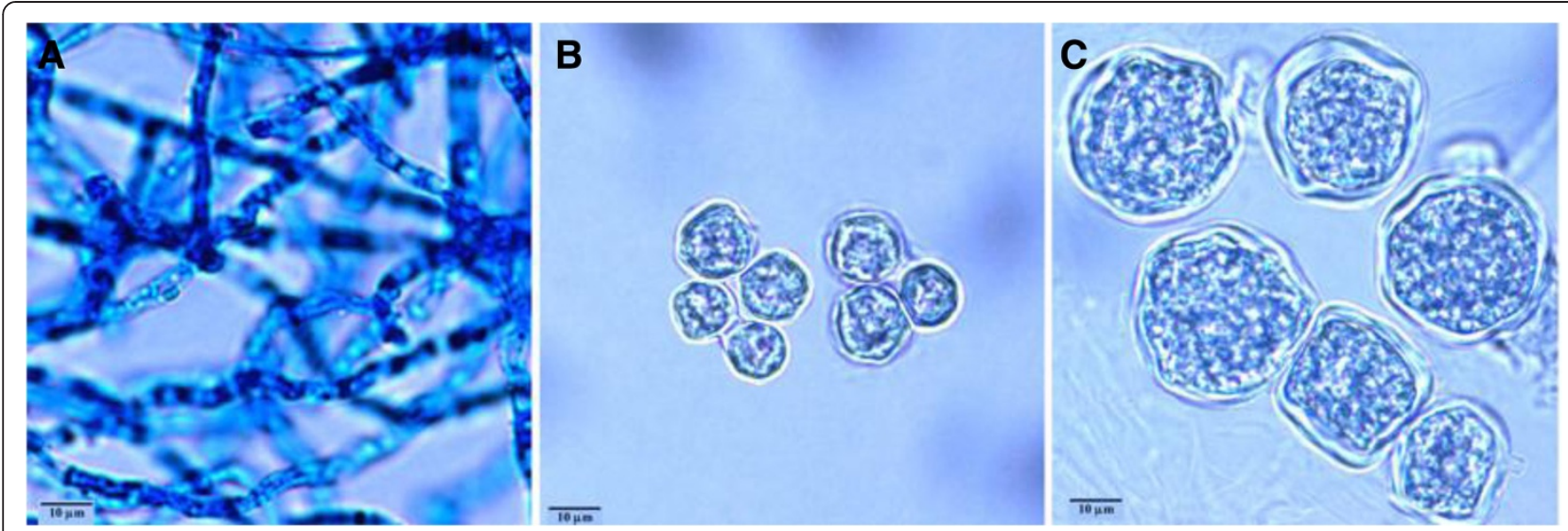

Figure 1 Photomicrographs of C. immitis strain RS mycelium and spherules after $\mathbf{2}$ and $\mathbf{8}$ days of culture. Notice the large increase in size as the spherules mature.

Figure S1. Fungal morphologic stage was the dominant determinant of the pattern of gene expression.

Genes that were significantly differentially expressed $(\mathrm{p}<0.05)$ between the three conditions (mycelia, spherules on day 2 and 8) were identified in a supervised approach using a one-way ANOVA with appropriate corrections for multiple testing (see Methods). All the up- and downregulated genes differentially expressed between each of the three conditions are detailed in Additional file 4: Table S2. A heatmap depicting expression levels in each sample for the top 100 differentially expressed genes is presented in Figure 2. The heatmap indicates there was limited variation in gene expression across the four replicates within each of the three conditions, suggesting that the data was highly reproducible. Multiple patterns of gene expression are evident comparing the three different conditions we studied. One cluster of genes was expressed to a lesser extent in the mycelia condition and a greater extent in both spherule conditions and another cluster of genes were expressed at a higher level in mycelia than in spherules. The expression of four genes (CIMG_08103, CIMG_09765, CIMG_10037, CIMG_10264) exhibiting the upregulated pattern was confirmed by RT-qPCR (see Figure 3 below).

There were a total of 2208 genes (22\% of the genome) that were differentially expressed between spherules at one or both the time points we studied and mycelia. Figure 4 shows Venn diagrams depicting up- and downregulated genes in day 2 and day 8 spherules compared to mycelia. About a third of the differentially expressed genes were up- or downregulated in both day 2 and day 8 spherules compared to mycelia. However, similar numbers of genes were exclusively upregulated in either day $2(\mathrm{~N}=443)$ or day $8(\mathrm{~N}=319)$ spherules, or exclusively downregulated at either day $2(\mathrm{~N}=565)$ or day $8(\mathrm{~N}=233)$ spherules. The difference in gene expression between day 2 and day 8 spherules was apparent when we compared day 2 and 8 spherules directly to each other; 1,197 differentially expressed genes $(12 \%$ of the total genome) were identified (Additional file 4: Table S2). Therefore, although gene expression by environmental form of the fungus and the parasitic form were quite distinct as might be expected, gene expression by young and mature spherules was also quite different from each other. Not only were there differences in which genes were expressed at each stage, but also the degree of modulation was large. For example, the maximum difference in expression of a gene (CIMG_10264) between day 2 spherules and mycelia was 48.6 fold and the median modulation between mycelia and day 2 spherules was 3.26.

A recent paper by Whiston et al. assessed transcription in C. immitis and C. posadasii mycelia and day 4 spherules by RNA-seq [13]. We have compared our results to theirs. The two studies used different methods for assessing changes in gene expression. We used microarray technology to estimate transcript abundance while Whiston et al. used RNA-seq to estimate transcript abundance [13]. The literature suggests that these methods should yield comparable results [24]. Despite this difference in methodology, we confirmed the upregulation of $25 \%$ of the genes that Whiston found to be upregulated in spherules. Conversely, $43 \%$ of genes that we have found to be upregulated in day 2 and day 8 spherules were also upregulated in day 4 spherules in the Whiston study (Additional file 5: Figure S2). Despite the differences in the two studies many of our conclusions are similar (see below).

We know from previous experiments that some genes are overexpressed in spherules compared to mycelia. Some of these genes, such as the spherule outer wall glycoprotein (CIMG_04613) [25] and the parasitic-phase specific protein PSP-1 (CIMG_05758) [26] were up regulated more than four fold in spherules in this experiment 


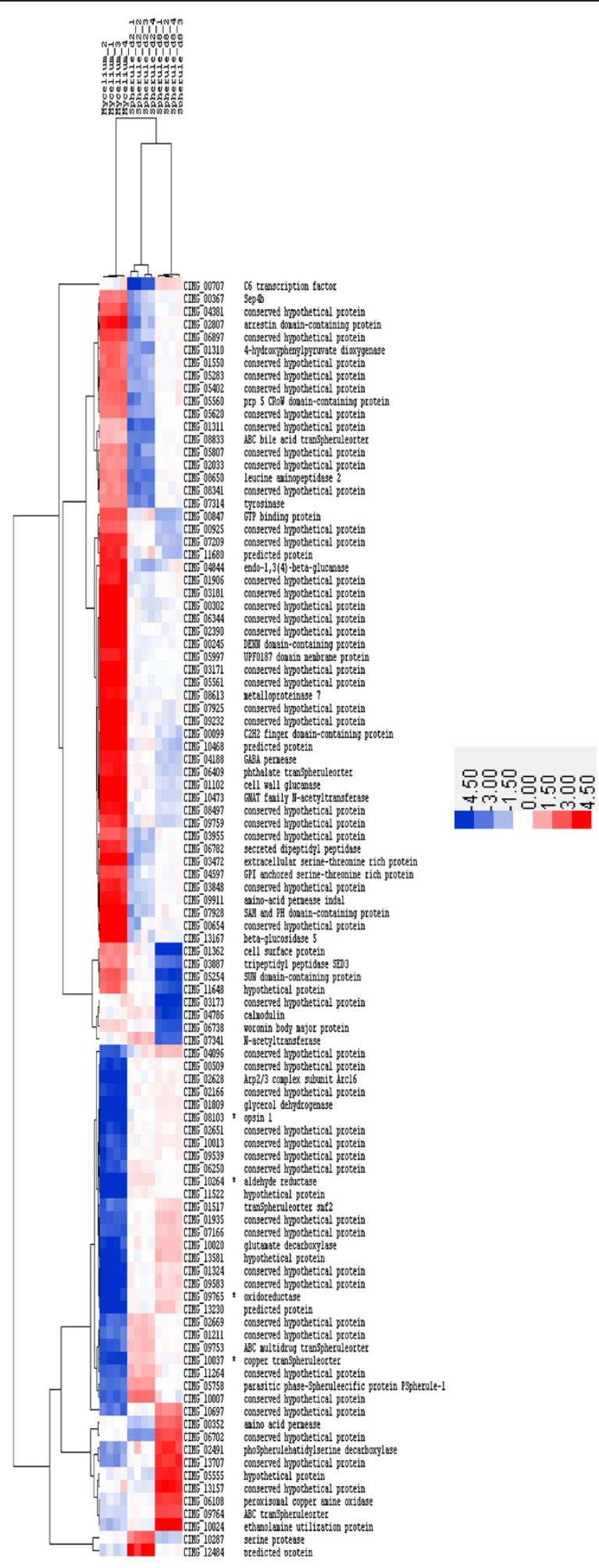

Figure 2 (See legend on next page.) 
(See figure on previous page.)

Figure $2 \mathrm{~A}$ heatmap depicting expression levels of genes in mycelia, day 2 spherules and day 8 spherules for the top 100 genes that were differentially expressed between mycelia, day 2 spherules and day 8 spherules. Fold changes were calculated for day 2 spherules vs mycelia and day 8 spherules vs mycelia. For each gene, the absolute peak log 2 fold change (FC) was identified across the three conditions and the raw expression values for the top 100 were log transformed and median-centered and included in the heatmap. Hierarchical clustering of genes and array samples based on their expression profiles is reflected in the dendrograms to the left and the top of the heatmap respectively and was performed by calculating distances using the Pearson correlation metric and then clustering distances using the average linkage method. The expression of genes marked with an asterisk (*) was confirmed by RT-qPCR. The scale is shown: red shading indicates greater expression blue shading represents lesser expression.

(Additional file 4: Table S2). Other genes, such as the metalloproteinase Mep1 (CIMG_06703), which has been found to be expressed at high levels in endosporulating spherules in C. posadasii was not found to be overexpressed in this experiment [27]. We also examined the expression level of the Mep1 gene by RT-qPCR and found that its expression was slightly downregulated in spherules compared to mycelia, rather than upregulated as previously reported (see below). Whiston et al. also examined the expression of this gene and found that it was upregulated in C. posadasii spherules but not $C$. immitis spherules [13].

\section{Confirmation of differential expression by RT-qPCR}

Twenty-four differentially expressed genes as detected by microarray analysis were selected for confirmation by RT-qPCR (Figure 3). Genes were selected for RT-qPCR confirmation of gene expression based on the magnitude of fold change (up- or downregulation) between mycelia and day 2 spherules, mycelia and day 8 spherules, and day 2 and day 8 spherules, and their identification in the PFAM or GO analysis. The significant differential expression ( $\mathrm{p}<0.05, t$-test) of each of these 24 genes was confirmed for at least one of the three comparison groups. In the majority of cases, RT-qPCR analysis detected larger differences in expression than microarray analysis. This is probably because RT-qPCR has a greater dynamic range than microarray does [28].

\section{PFAM analysis}

\section{Day 2 and day 8 spherules vs mycelia}

Functional enrichment analysis of PFAM families is shown in Table 1. Genes in the thioesterase superfamily are upregulated in day 2 spherules compared to mycelia. This family of proteins hydrolyzes long chain fatty acyl-CoA thioesters and is also involved in hydrolysis of fatty acids from $\mathrm{S}$-acylated cysteine residues in proteins, with a strong preference for palmitoylated G-alpha proteins over other acyl substrates [29]. Upregulation of genes involving lipid metabolism is reasonable since spherules contain a much higher percentage of lipids than mycelia [30].

The short chain dehydrogenases family was also upregulated in day 2 spherules (maximum upregulation 10.27 fold, CIMG_09765). This family of enzymes catalyzes oxidation/reduction reactions of alcohols and cyclic compounds. Up regulation of this family of enzymes seems plausible given the shift in growth conditions from air which contains less than $0.05 \% \mathrm{CO}_{2}$ (mycelial growth) to $14 \% \mathrm{CO}_{2}$ (spherule growth) which mimics the shift in oxidation/reduction potential that occurs when the organism grows in the mammalian host. The aldol-keto reductase family was also significantly enriched in both day 2 and day 8 spherules. These genes were also found to be upregulated in spherules by Whiston et al. [13]. This protein family plays a role in reducing oxidative stress [31] and may be required for resistance to the oxidative burst in mammals

\section{Upregulated genes}

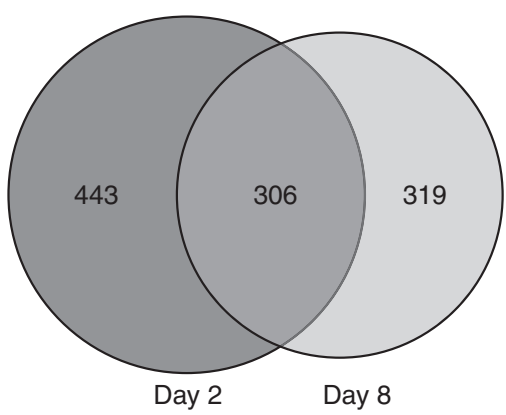

Downregulated genes

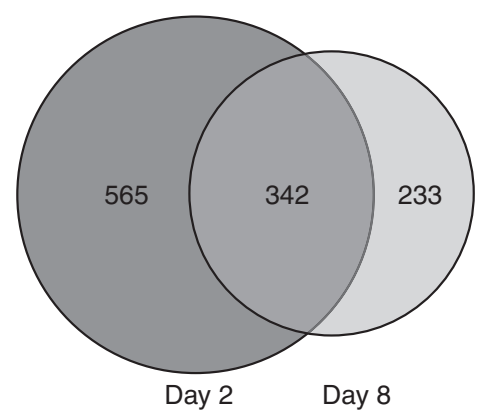

Figure 3 Venn diagrams showing the number of genes that are differentially expressed in day 2 spherules and day 8 spherules compared to mycelia. The number of up- or downregulated genes in shown. The procedures for determining up- or downregulation are in the methods section. 


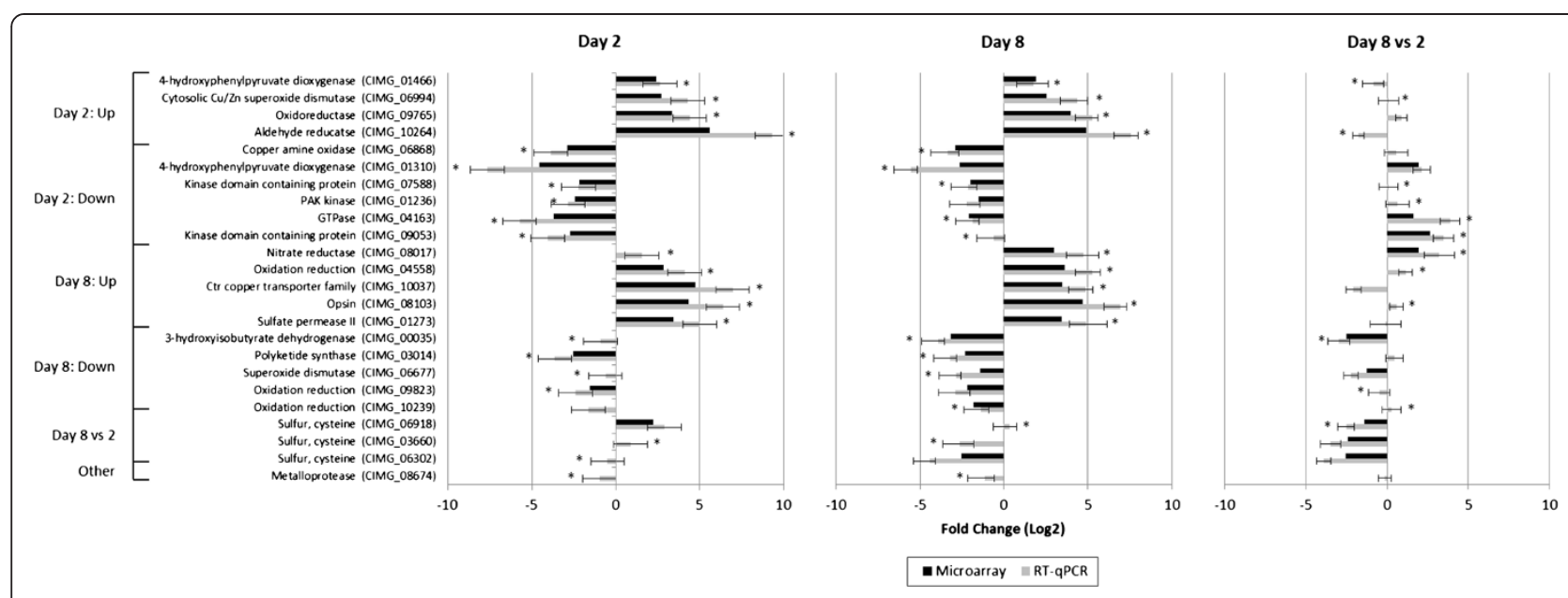

Figure 4 Confirmation of gene expression differences by RT-qPCR between day 2 spherules vs mycelia, day 8 spherules vs mycelia and day 8 vs day 2 spherules. The figure shows a comparison between the fold change for each gene for RT-qPCR data (grey bars) and microarray data (black bars) between the different conditions. RT-qPCR gene expression data $\left(2^{-\Delta \Delta C T}\right)$ was averaged within conditions and then used to calculate $\log _{2}$ fold change values between the different conditions for direct comparison to microarray data. A positive fold change indicates the gene was expressed to a greater extent within a condition. An asterisk $\left(^{*}\right)$ indicates that the gene was significantly differentially expressed ( $p<0.05, t$-test) and the error bars on the RT-qPCR data represent the standard deviation between the biological replicates of mycelia, spherules at day 2 and spherules at day 8 .

Table 1 PFAM functional enrichment

\begin{tabular}{|c|c|c|c|c|c|c|}
\hline PFAM Term & $\begin{array}{l}\text { \# Specified } \\
\text { Genes }\end{array}$ & $\begin{array}{l}\text { Whole } \\
\text { Genome }\end{array}$ & $\begin{array}{c}\text { Specified } \\
\text { Gene \% }\end{array}$ & $\begin{array}{c}\text { Whole } \\
\text { Genome \% }\end{array}$ & $P$ Value & $\begin{array}{c}\text { Corrected } \\
\text { P Value }\end{array}$ \\
\hline \multicolumn{7}{|l|}{ Day 2 Spherules Upregulated } \\
\hline Thioesterase superfamily (4HBT) & 5 & 6 & 0.99 & 0.06 & 0.0 & 0.0010 \\
\hline Short chain dehydrogenase & 11 & 57 & 2.19 & 0.58 & 0.0 & 0.04 \\
\hline Aldol-keto_reductase & 6 & 13 & 1.19 & 0.13 & 0.0 & 0.0080 \\
\hline \multicolumn{7}{|l|}{ Day 8 Spherules Upregulated } \\
\hline MFS_1 & 14 & 140 & 3.85 & 1.43 & 0.0 & 0.131 \\
\hline Aldol-keto_reductase & 5 & 13 & 1.37 & 0.13 & 0.0 & 0.018 \\
\hline \multicolumn{7}{|c|}{ Day 8 vs 2 Spherules Upregulated } \\
\hline $\mathrm{C} 2$ & 6 & 11 & 0.96 & 0.11 & 0.0 & 0.0090 \\
\hline PHD & 8 & 16 & 1.29 & 0.16 & 0.0 & 0.0010 \\
\hline $\mathrm{SH} 3 \_1$ & 8 & 24 & 1.29 & 0.25 & 0.0 & 0.027 \\
\hline Pkinase & 21 & 92 & 3.38 & 0.94 & 0.0 & 0.0 \\
\hline \multicolumn{7}{|l|}{ Day 2 Spherules Downregulated } \\
\hline $\mathrm{PH}$ & 8 & 16 & 0.93 & 0.16 & 0.0 & 0.011 \\
\hline SH3_1 & 14 & 24 & 1.63 & 0.25 & 0.0 & 0.0 \\
\hline $\mathrm{SH} 3 \_2$ & 11 & 18 & 1.28 & 0.18 & 0.0 & 0.0 \\
\hline Pkinase & 23 & 92 & 2.68 & 0.94 & 0.0 & 0.0010 \\
\hline $\mathrm{zf}-\mathrm{C} 2 \mathrm{H} 2$ & 19 & 53 & 2.21 & 0.54 & 0.0 & 0.0 \\
\hline \multicolumn{7}{|l|}{ Day 8 Spherules Downregulated } \\
\hline Kinesin & 6 & 10 & 1.14 & 0.1 & 0.0 & 0.0020 \\
\hline \multicolumn{7}{|c|}{ Day 8 vs 2 Spherules Downregulated } \\
\hline None & & & & & & \\
\hline
\end{tabular}


or to mitochondrial generated reactive oxygen species. C. immitis spherules are more resistant to oxidative killing in vitro than Aspergillus fumigatus spores [32].

The major facilitator super family (MFS-1) that was enriched in day 8 spherules is an important transporter of small molecules and includes a number of transporters for uptake as well as efflux [33]. Two highly upregulated genes are sugar transporters (CIMG_03001 and CIMG_08310). A nicotinic acid transporter (CIMG_06071) and a sialate transporter (CIMG_03956) were also upregulated. The nicotinic acid transporter is presumably involved in NAD metabolism [34]; we have been unable to find a role for the sialate transporter in fungi in the literature.

The pleckstrin domain occurs in a wide range of proteins involved in intracellular signaling or as constituents of the cytoskeleton. Pleckstrin domain transcripts were downregulated in day 2 spherules; in fact, one pleckstrin domain gene is the most downregulated of all the day 2 genes (CIMG_07982, -53.53 fold). The downregulated pleckstrin domain containing genes may be required for polar mycelial growth but not isotropic spherule growth. One downregulated gene in this family is the anucleate primary sterigmata protein A (CIMG_06141, -4.93), which is critical for movement of nuclei into spores on the sterigmata of $A$. nidulans [35]. This gene may well be required for arthroconidia formation in C. immitis mycelia but not endospore formation in spherules.

A significant proportion of proteins containing $\mathrm{SH} 3$ domains were downregulated in day 2 spherules. SH3 protein families include some protein kinases, phosphoinositol 3 kinases, Ras GTPase activating proteins, and the guanine nucleotide exchange factors $c d c 24$ and $c d c 25$ [36]. Two of these genes, CIMG_04361 and CIMG_04531, were downregulated in day 2 spherules. CIMG_04531 is annotated as a polarized growth protein, and is highly homologous to cytoskeleton assembly proteins in many fungi. CIMG_02193 is cytoskeletal protein SLA1 and it is downregulated ( -4.61 fold change) in day 2 spherules. Perhaps these proteins predispose to polar mycelial growth rather than isotropic spherule growth.

On the whole, the protein kinase family is downregulated in day 2 spherules. (This gene family was also detected by GO enrichment analysis in day 2 spherules but the $\mathrm{p}$-value did not achieve significance with the $\mathrm{BH}$ correction. The two analyses identified almost identical sets of genes.) Examining the up- and downregulated genes, we found that 23 genes were downregulated $(-7.84$ to -2.71 fold) and only two were upregulated (4.55 to 2.48 fold) (Table 2). Whiston et al. also found that 10 of these protein kinase genes were downregulated in spherules [13]. Four of the most downregulated genes were homologs of S. cerevisiae genes involved in sex or meiosis (indicated by an asterisk in Table 2). C. immitis has all the genes required for a sexual cycle [37] and has been shown to recombine in nature [38], but the sexual cycle has never been observed. Six of the downregulated protein kinase genes were homologs of $S$. cerevisiae genes involved in mitosis (indicated by a double asterisk in Table 2). Presumably some of these genes may interfere with arthroconidia conversion to spherules. The idea that there is more DNA replication in mycelia than in spherules has been previously proposed [5]. Of the two upregulated kinases, only CIMG_05990 (GCN2) has an ortholog in budding yeast. This kinase phosphorylates eIF2 in response to amino acid starvation [39]. Increased expression of GCN2 coupled with decreased expression of CIMG_08909, a sky1p ortholog involved in mRNA splicing [40], is consistent with the hypothesis that the rate of protein production in day 2 spherules is lower than in mycelia Additional file 2: Table S3 lists the functional classification of all of the $184 \mathrm{C}$. immitis protein kinases and their S. cerevisiae homologs. 126 of these are eukaryotic protein kinases (ePKs) and 58 are atypical protein kinases (aPK). Of the ePK there are 47 novel kinases: 17 SRPKLs (serine/arginine rich protein kinase-like), 6 PezKs (pezizomycotina kinases) and 24 unclassified kinases designated as 'Other'. We believe these 47 kinases to be novel because we did not observe orthologs in the species used for comparison, and they do not match families in kinase. com. There are 38 aPKs from well-known families, and 20 FunK1s (fungal kinase 1s) from a family recently described in Coprinopsis cinerea [41] and Paracoccidioides [42]. Examining the classification of the differentially expressed protein kinases in day 2 spherules we found that $50 \%$ of STE11 kinases, $40 \%$ of the STE2O kinases and none of the STE7 kinases were downregulated compared to mycelia. $40 \%$ of the CAMK/ CAMKL kinases are downregulated. Although the numbers are small, most of the protein kinases in the other/ WEE, other/RAN and other/NAK classifications were downregulated.

$\mathrm{C} 2 \mathrm{H} 2$ zinc finger domain containing proteins were downregulated in day 2 spherules. Most of the proteins containing this domain are transcription factors and the zinc finger is involved in DNA binding [43,44]. Some of the genes that were downregulated include the transcription factors CIMG_04642 (-9.24, FlbC), CIMG_03725 $(-5.06$, zinc finger transcription factor $\mathrm{PaCC})$ and CIMG_06050 (-3.06, transcription factor steA). In fact, $s t e A$ is a negative regulator of transcription in Aspergillus, so downregulation of this gene probably results in upregulated transcription of some genes [45]. Ste12 is the Saccharomyces homolog of this gene [46]. Ste12 is involved in the mating response and is involved in the upand downregulation of many genes. Eight of these 19 $\mathrm{C} 2 \mathrm{H} 2$ zinc finger genes were also found to be downregulated in spherules by Whiston et al. [13]. 
Table 2 Modulated protein kinases in day 2 and day 8 spherules

\begin{tabular}{|c|c|c|c|c|c|}
\hline Gene ID & $\mathrm{FC}^{\mathrm{a}}$ & $\mathrm{FC}^{\mathrm{b}}$ & C. immitis annotation & Classification gene & S. cerevisiae \\
\hline CIMG_05093 & -7.84 & 2.78 & Serine/threonine-protein kinase; meiosis induction protein kinase & CMGC/RCK/MAK & IME2 * \\
\hline CIMG_09053 & -6.68 & 6.18 & Kinase domain containing protein & CAMKNNNK1 & NNK1 \\
\hline CIMG_07296 & -5.60 & 5.26 & Protein kinase domain containing protein & CAMK/CAMKL/MARK & YPL150W \\
\hline CIMG_01236 & -5.46 & - & PAK kinase & STE/STE20/PAKA & STE2O * \\
\hline CIMG_00940 & -5.28 & - & Protein kinase & Other/WEE/SWE1 & SWE1 ** \\
\hline CIMG_07521 & -4.67 & 2.94 & Protein kinase domain containing protein; serine/threonine protein kinase 24 & STE/STE20/YSK & SPS1* \\
\hline CIMG_04027 & -4.65 & 3.81 & serine/threonine protein kinase ssp1 & Other/CAMKK & None \\
\hline CIMG_03267 & -4.55 & - & serine/threonine protein kinase & CAMKVCAMKL/Kin4 & KIN4 $4^{* *}$ \\
\hline CIMG_07588 & -4.52 & - & Kinase domain containing protein; checkpoint kinase & Other/TTK & MPS1 ** \\
\hline CIMG_01204 & -4.34 & 4.02 & protein kinase & AGC/YANK & None \\
\hline CIMG_08909 & -4.14 & 3.06 & Protein kinase, sky 1 & CMGC/SRPK & SKY1 \\
\hline CIMG_03947 & -4.04 & 3.64 & serine/threonine protein kinase & CAMK/CAMKL/PASK & PSK1 \\
\hline CIMG_03602 & -3.98 & 3.70 & Ran1-like protein kinase & Other/RAN/VHS1 & VHS1 ** \\
\hline CIMG_04103 & -3.97 & - & cytokenesis protein sepH & STE/STE11/CDC15 & $C D C 15^{* *}$ \\
\hline CIMG_08220 & -3.96 & 6.13 & serine/threonine protein kinase ATG1 & Other/ULK/ULK & ATG1 \\
\hline CIMG_06932 & -3.81 & 2.58 & MAP kinase kinase kinase SskB & STE/STE11/MEKK4 & SSK2 \\
\hline CIMG_13010 & -3.74 & 3.93 & serine/threonine protein kinase & Other/RAN/KSP1 & $K S P 1 *$ \\
\hline CIMG_09191 & -3.52 & 2.50 & Protein kinase & Other/HAL/HRK1 & HRK1 \\
\hline CIMG_09469 & -3.36 & - & Kinase domain containing protein & Other/PEK & None \\
\hline CIMG_03857 & -3.08 & - & Kinase domain containing protein & Other/NAK/BIKE & PAK1 \\
\hline CIMG_02369 & -3.05 & - & Response regulator receiver RIM15p & AGC/NDR/RIM15 & RIM15** \\
\hline CIMG_05623 & -2.74 & - & Serine threonine protein kinase & CAMK/CAMKL/AMPK & SNF1 \\
\hline CIMG_00136 & -2.71 & - & Kinase domain containing protein & CMGC/DYRK/DYRK2 & YAK1 \\
\hline CIMG_02925 & -4.55 & - & Protein kinase domain containing protein & CMGC & None \\
\hline CIMG_05694 & 3.01 & -3.83 & Protein kinase domain containing protein & CMGC/SRPKL1 & None \\
\hline CIMG_05990 & 2.48 & - & RWD domain protein & Other/PEK/GCN2 & GCN2 \\
\hline
\end{tabular}

* Indicates a gene involved in the sexual cycle in Saccharomyces; ** Indicates a gene involved in mitosis in Saccharomyces; a) Indicates a comparison between day 2 spherules and mycelia; b) indicates a comparison between day 8 and day 2 spherules; --, indicates that the gene is not modulated.

\section{Day 8 spherule/day 2 spherule comparison}

Several of the gene families that were downregulated in day 2 spherules were upregulated in the day 8 spherules (Table 1). Examples are the Ras GTPase activating proteins, the guanine nucleotide exchange factors $c d c 24$ and $c d c 25$ [36]. 13 of 19 of the kinases downregulated in the day 2 spherules had returned to mycelial levels in day 8 spherules (Table 2). Two genes in this family were downregulated in both day 2 and day 8 spherules: CIMG_00940 (-5.28 fold in day 2 spherules and -10.04 in day 8 spherules both compared to mycelia) and CIMG_04103 (-3.97 fold in day 2 spherules and -6.75 in day 8 spherules both compared to mycelia). CIMG_00940 was also found to be downregulated in spherules by Whiston et al. [13]. CIMG_00940 is a Swe1 kinase and CIMG_04103 is a STE/STE11/CDC15 kinase. Both of these genes are involved in regulation of mitosis [47-49]. One function of Wee kinases in S. cerevisiae is to prevent small cells from entering mitosis [50]; endospores are very small so downregulation of this gene may be important for endospore division. A function of the CDC15 kinases is to bind the spindle pole body and facilitate exit from mitosis [49]. There is no obvious reason why this kinase should be downregulated in the internally dividing spherule.

\section{Gene ontology analysis}

\section{Mycelia/day 8 spherules comparison}

The gene ontology (GO) terms significantly overrepresented in lists of differentially expressed genes identified between mycelia and either day 2 or day 8 spherules, as well as between day 2 and day 8 spherules, were identified using BiNGO [18]. There were no GO terms that survived FDR correction between mycelia and day 2 spherules but a large number of significant terms were identified between mycelia and day 8 spherules (Additional file 6: Figure S3). The most significant enriched GO term was "small molecule metabolic process" (corrected $\mathrm{p}=0.004$ ). Thirty-one members of this heterogeneous set of genes were upregulated and 75 were downregulated. Twelve of the downregulated genes coded for nucleotide synthesis or DNA replication. For example, a homeobox domain-containing 
protein was downregulated -8.68 fold (CIMG_09071); thymidylate synthase was down -3.57 fold (CIMG_08646); cell division control protein $C d c 6$ was down -3.05 fold (CIMG_07523) and DNA topoisomerase 2 was down -3.09 fold (CIMG_02836). This suggests that the rate of DNA synthesis is slower in the day 8 spherules than in mycelia. 10 genes coding for amino acid synthesis were downregulated as well. This suggests that not only is DNA synthesis relatively slow compared to mycelia but protein synthesis is too. Other genes involved in vitamin synthesis and energy generation were also downregulated. This is consistent with the notion that day 8 spherules have produced their endospores. Rupturing and releasing endospores should not be a metabolically expensive process. The observation that MFS-1 sugar transporters are upregulated suggests that that the low metabolic needs may not be universal.

The most strongly upregulated genes in day 8 spherules with the GO term "small metabolic process" included glutamate decarboxylase (21.47), three $\mathrm{ABC}$ transporters and parasitic phase specific protein-1 (6.66) previously described by Delgado [26]. The PSP-1 gene is also upregulated in day 2 spherules and in day 4 spherules as reported by Whiston et al. [13]. PSP-1 contains a RTA-1 domain, which is involved in resistance to 7-aminocholesterol [51]. This family of proteins has multiple membrane spanning domains and is thought to be involved in binding 7-aminocholesterol and related substances and preventing toxicity. They are not thought to be efflux pumps [51].

A group of genes assigned the GO term "carbohydrate metabolic processes" was also enriched in the day 8 spherules dataset. 15 genes were upregulated and 17 genes were downregulated. The upregulated genes included polysaccharide deacetylase (CIMG_02628, 34.82) and 1,4 ( $\alpha$ )-amylase (CIMG_03529, 2.70). The most striking downregulated gene in this group is calmodulin (CIMG_04786, -10.38). Two other genes coding for calmodulin (CIMG_02413 and CIMG_08162) are not differentially expressed in day 8 spherules. We looked for differential expression of six calmodulin-dependent kinases and found that they were not up- or downregulated. Calmodulin-dependent signaling enzymes are required for growth of Cryptococcus neoformans at $37^{\circ} \mathrm{C}$ [52] and for conversion of Sporothrix shenkii from mold to yeast [53].

Another enriched GO term in day 8 spherules was "oxidation-reduction processes" (corrected p-value = 0.012). In this group of genes, twenty-seven genes were upregulated in spherules and 27 were downregulated in spherules compared to mycelia. The five most upregulated genes were aldol-keto reductases (maximum 30.2 fold), alcohol dehydrogenases (maximum 11.65 fold) and nitrate reductase (8.06). The aldol-keto reductases were also identified in the PFAM functional enrichment in day 2 and day 8 spherules (Table 1). All these responses make sense in terms of the difference in growth conditions of mycelia (grown in air containing less than $0.05 \% \mathrm{CO}_{2}$ ) and spherules (grown in $14 \% \mathrm{CO}_{2}$ in air). These responses also seem reasonable in terms of the spherule living in the high $\mathrm{CO}_{2}$ environment of the mammalian host compared to the mycelia living in the soil. Other upregulated genes include Y2O (CIMG_04756), which was upregulated 11.18 fold in day 2 spherules and 6.81 fold in day 8 spherules. This gene was also upregulated in spherules in the Whiston study [13]. This gene codes for a flavodoxin that plays a role in the cellular responses to oxidative stress [54]. A homolog of this gene is highly upregulated in the yeast phase of $P$. brasiliensis [54]. Presumably this protein is protecting the fungus against oxidative attack by the mammalian host. Additional genes coding for response to oxidative stress that were upregulated in day 8 spherules include a $\mathrm{Cu} / \mathrm{Zn}$ super-oxide dismutase (CIMG_06994, 5.88) and a catalase. CIMG_06994 was up regulated 6.51 fold in day 2 spherules too. This gene is highly homologous to the extracellular SOD3 $(\mathrm{e}=4 \times$ $10^{-50}$ ) recently identified as a secreted protein in the Histoplasma yeast phase [55]. Gene deletion experiments have shown that this gene is important for defense against oxidative stress [56]. SOD3 is a secreted protein in H. capsulatum; CIMG_06944 has a predicted signal sequence suggesting that it is a secreted protein too. Extracellular SOD may be more protective against mammalian oxidative stress as suggested by Youseff [56]. Presumably the $C$. immitis homolog of SOD3 is up regulated to protect the spherule against oxidative stress in the host. C. immitis also contains genes highly homologous to $A$. fumigatus SOD2 and SOD4 but neither of those is up- or downregulated.

Several NAD or NADPH dependent oxireductases were downregulated $3-8$ fold in day 8 spherules. An NADPH oxidase was downregulated 3.48 fold. This enzyme makes reactive oxygen intermediates in fungi just as it does in mammalian phagocytes [57]. Reactive oxygen intermediates are important for apical growth and formation of spores in filamentous fungi $[57,58]$. It is possible that the NADP oxidase may interfere with isotropic spherule growth and differentiation.

\section{Day 8/day 2 spherule comparison}

Several GO terms were significantly over-represented (FDR corrected p-value $<0.05$ ) in the list of genes differentially expressed between day 8 and day 2 spherules. The most significant enriched GO term was "sulfur compound metabolic process" (corrected $\mathrm{p}$-value $=0.046$ ). Sixteen genes were downregulated in this data set and one was upregulated. We see downregulation of $5^{\prime}$-methylthioadenosine phosphorylase (CIMG_01361, -7.45 fold), phosphoadenosine 
phosphosulfate reductase (CIMG_00456, -4.65 fold), two genes coding for adenylyl-sulfate kinase (CIMG_00454, -4.22 fold and CIMG_06918, -2.65 fold) and sulfite reductase (CIMG_00269, -2.94 fold) in day 8 spherules. Two of these genes were upregulated in day 2 spherules compared to mycelia. All these genes are involved in accumulating sulfide. This suggests that $C$. immitis spherules have no difficulty accumulating enough sulfur for their needs as they mature.

\section{Upregulated or downregulated genes in day 2, day 4 and day 8 spherules}

We identified 153 genes that were upregulated more than two fold in day 2 spherules, day 8 spherules and day 4 spherules in the Whiston study [13]. 140 genes were downregulated more than two fold in all three spherule samples. $57 \%$ of the upregulated genes and $42 \%$ of the downregulated genes had no function annotation (Additional file 7: Table S4). Many of these unannotated genes were highly differentially expressed suggesting that they may be important for spherule development. One upregulated gene that has not been discussed is opsin-1 (CIMG_08103, maximal upregulation 25.72). This gene is closely related to the bacterial rhodopsin gene coding for G protein coupled receptors; its function in fungi has not been determined [59]. Another gene that was upregulated at all three spherule time points was the sulfite transporter Ssu1 (CIMG_05899, maximum upregulation 6.37). Downregulated genes of interest include several glucosidases, glucanases and a chitosanase. Two septin genes are downregulated in spherules. Septin genes are important regulators of the cytoskeleton and play a role in determining cell shape [60]. Why these genes are downregulated is unclear since the spherule is undergoing extensive cellular remodeling. Perhaps septins are required for polar growth and other regulators are needed for isotropic spherule growth. Further analysis of the relatively small group of genes that are consistently up- or downregulated throughout spherule development may be useful for understanding the pathogenic phase of this organism.

\section{Comparison of results to those obtained in other pathogenic fungi}

The dimorphic pathogenic fungi are phylogenetically closely related [61] so it is reasonable to ask if genes important for conidium to yeast transformation in those pathogens are also important for arthroconidia to spherule transformation in Coccidioides. One $H$. capsulatum gene that is required for mycelium to yeast transformation is the alpha amylase (AMY1) gene. This gene affects the amount of $\alpha(1,3)$ glucan in the yeast cell wall, and that carbohydrate appears to be important for the ability of the yeast to survive in macrophages and in mice [62]. This gene has a nearly identical homolog in C. immitis, CIMG_03142, that was upregulated 3.6 fold in day 2 spherules and 3.39 fold in day 8 spherules. Whiston et al. also found it to be upregulated in spherules [13]. Another H. capsulatum gene that is required for yeast formation is a glucan synthase (AGS1) gene [62]. This enzyme catalyzes the production of $\alpha(1,3)$ glucan in the cell wall that obscures the $\beta(1,3)$ glucan and prevents activation of innate immunity via the dectin-1 receptor [62]. C. immitis has an AGS1 gene (CIMG_13256) that was upregulated in the day 8 spherule ( 2.48 fold) but not day 2 spherules. Whiston et al. found this gene to be upregulated 1.93 fold in spherules compared to mycelia [13]. There is no literature describing the relative amounts of $\alpha(1,3)$ glucan and $\beta(1,3)$ glucan in $C$. immitis mycelia or spherules. We know, however, that there is enough exposed $\beta(1,3)$ glucan in Coccidioides spherules to stimulate macrophages to produce cytokines via dectin-1 [63].

Two genes coding for transcription factors, Ryp 2 and Ryp3, have been found to be essential for conversion from filaments to yeast in $H$. capsulatum [64]. These genes are overexpressed in the yeast phase of $H$. capsulatum [64]. C. immitis has nearly identical homologs of these genes but they were not overexpressed in either day 2 or day 8 spherules, suggesting that they may not be required for the transformation from mycelium to spherule.

Gene disruption experiments in $B$. dermatitidis have shown that a histidine kinase, DRK1, is required for the transformation from filaments to yeast [65]. It is not clear from the literature whether or not this gene is overexpressed in the $B$. dermatitidis yeast phase. $C$. immitis has a very closely related homolog of this gene (CIMG_04512) but it was not up or down regulated in day 2 or day 8 spherules. In another dimorphic pathogenic fungus, S. schenckii, the calcium/calmodulin kinase I gene (SSMK1) was found to be required for formation of yeast [53]. There are two genes in C. immitis that are highly homologous to the S. schenckii SSMK1 gene; neither one of these was up- or downregulated in day 2 or day 8 spherules.

A number of studies have been done studying the transcriptome of $P$. brasiliensis [66,67]. One study identified the 4-HPPD gene to be required for $P$. brasiliensis conidia to convert to yeast [66]. They found that the 4-HPPD gene expression was upregulated in the yeast form and that a biochemical inhibitor of this enzyme, nitisinone, inhibited mycelium conversion to yeast. 4-HPPD (E.C. 1.13.1127) is an enzyme that converts 4-hydroxyphenylpyruvate to homogentisate that is involved in the synthesis of tyrosine, phenylalanine, and ubiqinone (KEGG, wwww.genome.jp/keg).

There are two homologs of the 4-HPPD in the C. immitis genome, which have significantly different sequences. One 
of these, CIMG_01466 was upregulated 5.27 fold in day 2 spherules and 3.80 fold in day 8 spherules. This gene was also found to be upregulated in spherules by Whiston et al. [13]. The other homolog, CIMG_01310, was downregulated -23.67 fold in day 2 spherules and -6.09 fold in day 8 spherules. The biggest difference in sequence is that CIMG_01466 has two substantial deletions compared to CIMG_01310. These deletions flank the highly conserved site that is predicted to contact the active site metal ion [68]. Furthermore, CIMG_01466 had substitutions in the predicted metal ion contact site, suggesting that it may not be an active enzyme. Nevertheless, we tested the effect of nitisinone on mycelial growth and mycelium to spherule conversion. We found that nitisinone inhibits mycelial growth at concentrations as low as $1 \mu \mathrm{g} / \mathrm{ml}$ (Figure 5). Surprisingly, there was no effect on mycelium to spherule conversion (data not shown). This is distinctly different from the results seem in $P$. brasiliensis. Our data suggests that 4-HPPD enzyme activity is not required for mycelium to spherule conversion or the growth of spherules but it is important for mycelial growth.

\section{Conclusions}

Conversion from the arthroconidia phase to the parasitic spherule phase in C. immitis requires major transcriptional reprogramming with $22 \%$ of the entire genome being differentially expressed between the two conditions. Further, gene expression within spherules is dynamic with
$12 \%$ of the entire genome being differentially expressed as they mature from day 2 to day 8 . It is evident from the transcriptional profile at day 2 compared to mycelia that differentiation of $C$. immitis is associated with the regulation of specific genes. For example, a number of genes were downregulated during mycelia to spherule conversion including transcriptional repressors (genes encoding zinc finger proteins), pleckstrin domain containing genes, and genes coding for proteins with $\mathrm{SH} 3$ signaling domains. Additionally, twenty-four protein kinase genes homologous to $S$. cerevisiae genes coding for sexual or meiotic function or mitosis or filamentous growth are downregulated and may play a role in arthroconidia differentiation to spherules. About $75 \%$ of the protein kinase genes return to mycelial levels of expression in 8 day spherules, suggesting they may be important in arthroconidia to spherule differentiation but not in spherule maturation. Some genes are persistently upregulated or downregulated in spherules at both time points. These include some genes that have previously been shown to be important for yeast development in $H$. capsulatum such as amylase gene $A M Y-1$ [62]. An enzyme such as extra-cellular superoxide dismutase (SOD3), that provides protection against oxidative stress was also upregulated in both day 2 and day 8 spherules [56]. In contrast to Paracoccidioides brasiliensis, where inhibition of the enzyme 4-HPPD inhibits conversion of the mold to the yeast form [66], inhibition of the enzyme 4-HPPD

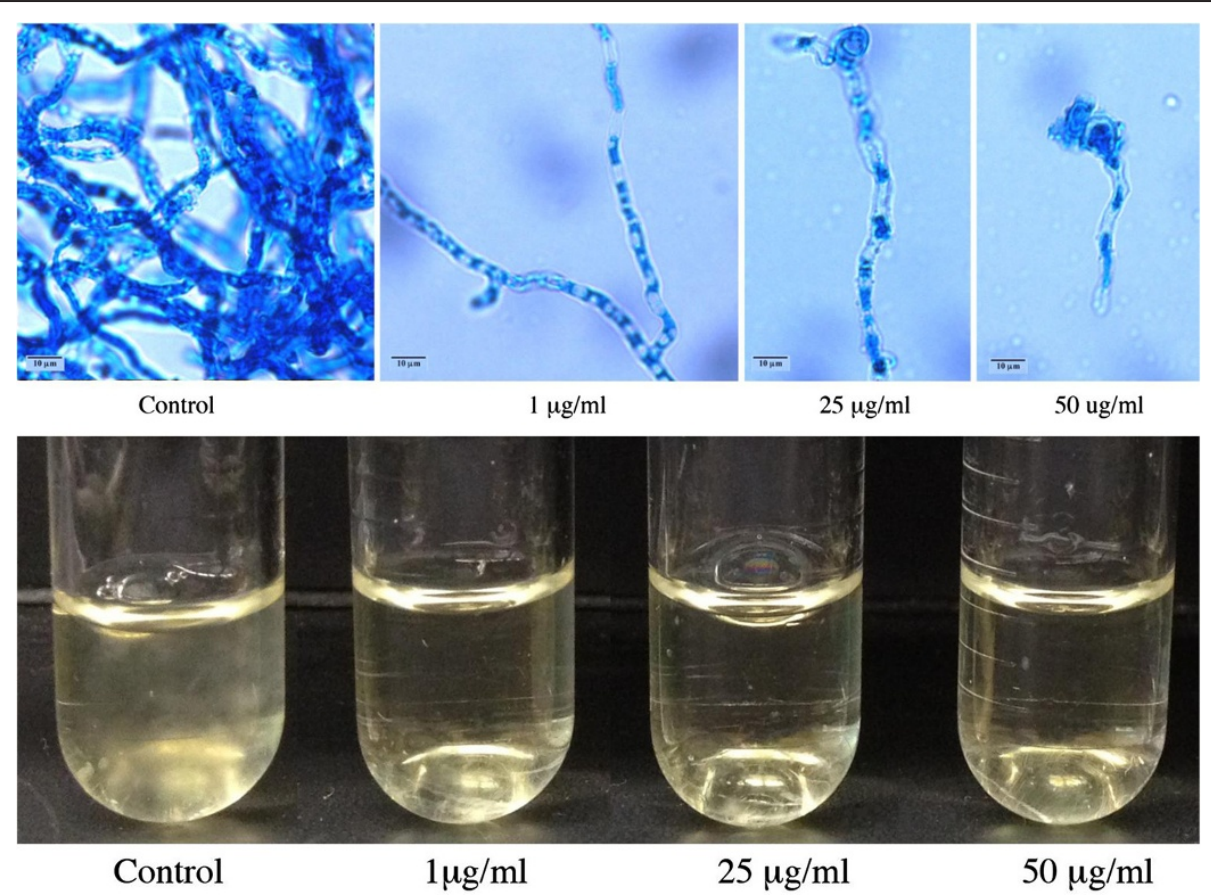

Figure $\mathbf{5}$ Inhibition of $\mathbf{C}$. immitis mycelial growth by nitisinone. Photomicrographs showing (A) mycelial growth in the presence of nitisinone at doses of $1 \mu \mathrm{g} / \mathrm{ml}, 25 \mu \mathrm{g} / \mathrm{ml}$ and $50 \mu \mathrm{g} / \mathrm{ml}$ compared to the control; (B) mycelial growth as measured by turbidity in the indicated concentrations of nitisinone compared to the control. 
inhibits mycelial growth in C. immitis but has no effect in arthroconidia to spherule conversion in $C$. immitis. Arthroconidia to spherule conversion in $C$. immitis is a complex process requiring modulation of a large number of genes.

\section{Additional files}

Additional file 1: Table S1. GO terms associated with C. immitis locus tags.

Additional file 2: Table S3. Classification of C. immitis protein kinases. Additional file 3: Figure S1. A dendrogram showing that unsupervised clustering using the expression of all genes on the microarray revealed that mycelia samples clustered distinctly from spherule samples. Furthermore, spherule samples formed two sub-clusters based on maturity.

Additional file 4: Table S2. Genes identified as differentially expressed between the three experimental conditions: day 2 spherule vs mycelia, day 8 vs mycelia spherule and day 8 spherule vs day 2 spherule.

Additional file 5: Figure S2. Two Venn diagrams revealing the partially overlapping pattern of gene expression between day 2 and day 8 spherules in this study and day 4 spherules in the Whiston et al. study [13].

Additional file 6: Figure S3. Hierarchical depiction of GO terms significantly over-represented in the set of genes that were differentially expressed with a fold change $\geq 2$ or $\leq-2$ between mycelia and day 8 spherules (A) or day 2 and day 8 spherules (B). The size of the node associated with each GO term is relative to the number of differentially expressed genes belonging to that term. The color scale indicates the level of significance associated with each node with red being the most significant.

Additional file 7: Table S4. Genes overexpressed in day 2 spherules, day 8 spherules and in day 4 spherules as reported by Whiston et al. [13].

\section{Abbreviations}

4-HPPD: 4-hydroxyphenylpyruvate dioxygenase; FC: Fold change; FDR: False discovery rate; GO: Gene ontology; GYE: Glucose yeast extract; ORF: Open reading frame; PFAM: Protein families.

\section{Competing interests}

The authors declare that they have no competing interests.

\section{Authors' contributions}

SV grew the mycelia and spherules, did the inhibition experiments and prepared the RNA; AS performed most of the bioinformatic analysis; JF participated in writing the manuscript; JG did the bioinformatic analysis of protein kinases; TK supervised the experimental work and analyzed the bioinformatic results; CW supervised the bioinformatic analysis; all of the authors participated in writing the manuscript. All authors read and approved the final manuscript.

\section{Acknowledgements}

We thank Daniel Neafsey and Diego Martinez (Broad Institute, Cambridge MA, 02141) for help retrieving data, reviewing this manuscript, and for providing us with the Trichophyton rubrum kinome ahead of publication, respectively. We also thank Gerald Manning (Salk Institute, San Diego, CA) for providing us with updated protein kinase classifications ahead of publication at http://kinase.com/. This project was supported by funds received from the State of California, Department of Public Health, Award No. 09-11657 (T.N.K.), a grant from the Academic Senate of the University of California (T.N.K.) and The Research Service of the Veterans Administration (J.F.). This work was also performed with the support of the Genomics Core at the UCSD Center for AIDS Research funded through the National Institutes of Health (Al36214) (C.W.). This material is based upon work supported in part by the Department of Veterans Affairs, Veterans Health Administration, Office of Research and Development.

\section{Author details}

'Department of Medicine, University of California San Diego, La Jolla, CA 92093, USA. ${ }^{2}$ Research Service, Veterans Affairs San Diego Healthcare System (111F), 3350 La Jolla Village Dr, San Diego, CA 92161, USA. ${ }^{3}$ Department of Pathology, University of California San Diego, La Jolla, CA 92093, USA. ${ }^{4}$ The Broad Institute, Cambridge, MA 02142, USA.

Received: 14 January 2013 Accepted: 20 May 2013

Published: 28 May 2013

\section{References}

1. Neafsey DE, Barker BM, Sharpton TJ, Stajich JE, Park DJ, Whiston E, Hung CY, McMahan C, White J, Sykes S, et al: Population genomic sequencing of Coccidioides fungi reveals recent hybridization and transposon control. Genome Res 2010, 20(7):938-946.

2. Fisher MC, Koenig GL, White TJ, San-Blas G, Negroni R, Alvarez IG, Wanke B, Taylor JW: Biogeographic range expansion into South America by Coccidioides immitis mirrors New world patterns of human migration. Proc Natl Acad Sci USA 2001, 98(8):4558-4562.

3. CDC: Increase in coccidioidomycosis - California, 2000-2007. MMWR Morb Mortal Wkly Rep 2009, 58(5):105-109.

4. Cole GT, Hung CY: The parasitic cell wall of Coccidioides immitis. Med Mycoll 2001, 39(Suppl 1):31-40

5. Cole GT, Sun SH: Arthroconidium-spherule-endospore transformation in Coccidioides immitis. In Dimorphism. Edited by Szaniszlo P. New York: Plenum; 1985:281-333.

6. Chang DC, Anderson S, Wannemuehler K, Engelthaler DM, Erhart L, Sunenshine $\mathrm{RH}$, Burwell LA, Park BJ: Testing for coccidioidomycosis among patients with community-acquired pneumonia. Emerg Infect Dis 2008, 14(7):1053-1059.

7. Chiller TM, Galgiani JN, Stevens DA: Coccidioidomycosis. Infect Dis Clin North Am 2003, 17(1):41-57. viii.

8. Kirkland TN, Fierer J: Coccidioidomycosis: a reemerging infectious disease. Emerg Infect Dis 1996, 2(3):192-199.

9. Smith CE, Pappagianis D, Levine HB, Saito M: Human coccidioidomycosis. Bacteriol Rev 1961, 25:310-320.

10. Kirkland TN, Fierer J: Inbred mouse strains differ in resistance to lethal Coccidioides immitis infection. Infect Immun 1983, 40:912-917.

11. Xue J, Chen X, Selby D, Hung CY, Yu JJ, Cole GT: A genetically engineered live attenuated vaccine of Coccidioides posadasii protects BALB/c mice against coccidioidomycosis. Infect Immun 2009, 77(8):3196-3208.

12. Converse $\mathrm{JL}$ : Effect of surface active agents on endosporulation of Coccidioides immitis in a chemically defined medium. J Bacteriology 1957, 74:106-107.

13. Whiston E, Zhang Wise H, Sharpton TJ, Jui G, Cole GT, Taylor JW: Comparative transcriptomics of the saprobic and parasitic growth phases in Coccidioides spp. PLoS One 2012, 7(7):e41034.

14. Sharpton TJ, Stajich JE, Rounsley SD, Gardner MJ, Wortman JR, Jordar VS, Maiti R, Kodira CD, Neafsey DE, Zeng Q, et al: Comparative genomic analyses of the human fungal pathogens Coccidioides and their relatives. Genome Res 2009, 19(10):1722-1731.

15. Woelk CH, Beliakova-Bethell N, Goicoechea M, Zhao Y, Du P, Rought SE, Lozach J, Perez-Santiago J, Richman DD, Smith DM, et al: Gene expression before HAART initiation predicts HIV-infected individuals at risk of poor CD4+ T-cell recovery. AIDS 2010, 24(2):217-222

16. Simon A, Biot E: ANAIS: analysis of NimbleGen arrays interface. Bioinformatics 2010, 26(19):2468-2469.

17. Klipper-Aurbach Y, Wasserman M, Braunspiegel-Weintrob N, Borstein D, Peleg S, Assa S, Karp M, Benjamini Y, Hochberg Y, Laron Z: Mathematical formulae for the prediction of the residual beta cell function during the first two years of disease in children and adolescents with insulindependent diabetes mellitus. Med Hypotheses 1995, 45(5):486-490.

18. Maere S, Heymans K, Kuiper M: BiNGO: a Cytoscape plugin to assess overrepresentation of gene ontology categories in biological networks. Bioinformatics 2005, 21(16):3448-3449.

19. Martinez DA, Oliver BG, Gräser Y, Goldberg JM, Li W, Martinez-Rossi NM, Monod M, Shelest E, Barton RC, Birch E, et al: Comparative genome analysis of Trichophyton rubrum and related dermatophytes reveals candidate genes involved in infection. MBio 2012, 3(5):e00259-12. doi:10.1128/mBio.00259-12. Print 2012.

20. Goldberg JM, Manning G, Liu A, Fey P, Pilcher KE, Xu Y, Smith JL: The dictyostelium kinome-analysis of the protein kinases from a simple model organism. PLoS Genet 2006, 2(3):e38. 
21. Manning G, Whyte DB, Martinez R, Hunter T, Sudarsanam S: The protein kinase complement of the human genome. Science 2002, 298(5600):1912-1934.

22. Petersen TN, Brunak S, von Heijne G, Nielsen H: SignalP 4.0: discriminating signal peptides from transmembrane regions. Nat Methods 2011, 8(10):785-786.

23. Livak KJ, Schmittgen TD: Analysis of relative gene expression data using real-time quantitative PCR and the 2(-Delta Delta $C(T))$ Method. Methods 2001, 25(4):402-408.

24. Wang Z, Gerstein M, Snyder M: RNA-Seq: a revolutionary tool for transcriptomics. Nat Rev Genet 2009, 10(1):57-63.

25. Hung C, Ampel NM, Christian L, Seshan KR, Cole GT: A major cell surface antigen of Coccidioides immitis which elicits both humoral and cellular immune responses. Infect Immun 2000, 68(2):584-593.

26. Delgado N, Hung CY, Tarcha E, Gardner MJ, Cole GT: Profiling gene expression in Coccidioides posadasii. Med Mycol 2004, 42(1):59-71.

27. Hung CY, Seshan KR, Yu JJ, Schaller R, Xue J, Basrur V, Gardner MJ, Cole GT: A metalloproteinase of Coccidioides posadasii contributes to evasion of host detection. Infect Immun 2005, 73(10):6689-6703.

28. Rajeevan MS, Vernon SD, Taysavang N, Unger ER: Validation of array-based gene expression profiles by real-time (kinetic) RT-PCR. JMD 2001, 3(1):26-31.

29. Smotrys JE, Linder ME: Palmitoylation of intracellular signaling proteins: regulation and function. Annu Rev Biochem 2004, 73:559-587.

30. Wheat RW, Tritschler C, Conant NF, Lowe EP: Comparison of Coccidioides immitis arthrospore, mycelium, and spherule cell walls, and influence of growth medium on mycelial cell wall composition. Infect Immun 1977, 17(1):91-97.

31. Chang Q, Petrash JM: Disruption of aldo-keto reductase genes leads to elevated markers of oxidative stress and inositol auxotrophy in Saccharomyces cerevisiae. Biochim Biophys Acta 2008, 1783(2):237-245.

32. Margolis DA, Viriyakosol S, Fierer J, Kirkland TN: The role of reactive oxygen intermediates in experimental coccidioidomycois in mice. BMC Microbiol 2011, 11:71.

33. Gaur M, Puri N, Manoharlal R, Rai V, Mukhopadhayay G, Choudhury D, Prasad R: MFS transportome of the human pathogenic yeast Candida albicans. BMC Genomics 2008, 9:579.

34. Bogan KL, Evans C, Belenky P, Song P, Burant CF, Kennedy R, Brenner C: Identification of Isn1 and Sdt1 as glucose- and vitamin-regulated nicotinamide mononucleotide and nicotinic acid mononucleotide [corrected] 5'-nucleotidases responsible for production of nicotinamide riboside and nicotinic acid riboside. J Biol Chem 2009, 284(50):34861-34869.

35. Fischer $\mathrm{R}$, Timberlake WE: Aspergillus nidulans apsA (anucleate primary sterigmata) encodes a coiled-coil protein required for nuclear positioning and completion of asexual development. J Cell Biol 1995, 128(4):485-498.

36. Mayer BJ, Baltimore D: Signalling through $\mathrm{SH} 2$ and $\mathrm{SH} 3$ domains. Trends Cell Biol 1993, 3(1):8-13.

37. Fraser JA, Stajich JE, Tarcha EJ, Cole GT, Inglis DO, Sil A, Heitman J: Evolution of the mating type locus: insights gained from the dimorphic primary fungal pathogens Histoplasma capsulatum, Coccidioides immitis, and Coccidioides posadasii. Eukaryot Cell 2007, 6(4):622-629.

38. Bowman BH, Taylor JW, White TJ: Molecular evolution of the fungi: human pathogens. Mol Biol Evol 1992, 9(5):893-904.

39. Menacho-Marquez M, Perez-Valle J, Arino J, Gadea J, Murguia JR: Gcn2p regulates a G1/S cell cycle checkpoint in response to DNA damage. Cell Cycle 2007, 6(18):2302-2305.

40. Siebel CW, Feng L, Guthrie C, Fu XD: Conservation in budding yeast of a kinase specific for SR splicing factors. Proc Natl Acad Sci USA 1999, 96(10):5440-5445.

41. Stajich JE, Wilke SK, Ahren D, Au CH, Birren BW, Borodovsky M, Burns C, Canback B, Casselton LA, Cheng CK, et al: Insights into evolution of multicellular fungi from the assembled chromosomes of the mushroom Coprinopsis cinerea (Coprinus cinereus). Proc Natl Acad Sci USA 2010, 107(26):11889-11894.

42. Desjardins CA, Champion MD, Holder JW, Muszewska A, Goldberg J, Bailao AM, Brigido MM, Ferreira ME, Garcia AM, Grynberg M, et al: Comparative genomic analysis of human fungal pathogens causing paracoccidioidomycosis. PLoS Genet 2011, 7(10):e1002345.

43. Krishna SS, Majumdar I, Grishin NV: Structural classification of zinc fingers: survey and summary. Nucleic Acids Res 2003, 31(2):532-550.

44. Christy B, Nathans D: DNA binding site of the growth factor-inducible protein Zif268. Proc Natl Acad Sci USA 1989, 86(22):8737-8741.

45. Vallim MA, Miller KY, Miller BL: Aspergillus SteA (sterile12-like) is a homeodomain- $\mathrm{C} 2 / \mathrm{H} 2-\mathrm{Zn}+2$ finger transcription factor required for sexual reproduction. Mol Microbiol 2000, 36(2):290-301.
46. Roberts RL, Fink GR: Elements of a single MAP kinase cascade in Saccharomyces cerevisiae mediate two developmental programs in the same cell type: mating and invasive growth. Genes Dev 1994, 8(24):2974-2985.

47. Wittenberg C, La Valle R: Cell-cycle-regulatory elements and the control of cell differentiation in the budding yeast. Bioessays 2003, 25(9):856-867.

48. La Valle R, Wittenberg C: A role for the Swe1 checkpoint kinase during filamentous growth of Saccharomyces cerevisiae. Genetics 2001, 158(2):549-562.

49. Konig C, Maekawa H, Schiebel E: Mutual regulation of cyclin-dependent kinase and the mitotic exit network. J Cell Biol 2010, 188(3):351-368.

50. Nurse P: Genetic control of cell size at cell division in yeast. Nature 1975, 256(5518):547-551.

51. Soustre I, Letourneux Y, Karst F: Characterization of the Saccharomyces cerevisiae RTA1 gene involved in 7-aminocholesterol resistance. Curr Genet 1996, 30(2):121-125.

52. Brown SM, Campbell LT, Lodge JK: Cryptococcus neoformans, a fungus under stress. Curr Opin Microbiol 2007, 10(4):320-325.

53. Rodriguez-Caban J, Gonzalez-Velazquez W, Perez-Sanchez L, GonzalezMendez R, Valle NR: Calcium/calmodulin kinase1 and its relation to thermotolerance and HSP90 in Sporothrix schenckii: an RNAi and yeast two-hybrid study. BMC Microbiol 2011, 11:162.

54. Daher BS, Venancio EJ, de Freitas SM, Bao SN, Vianney PV, Andrade RV Dantas AS, Soares CM, Silva-Pereira I, Felipe MS: The highly expressed yeast gene pby20 from Paracoccidioides brasiliensis encodes a flavodoxin-like protein. Fungal Genet Biol 2005, 42(5):434-443.

55. Holbrook ED, Edwards JA, Youseff BH, Rappleye CA: Definition of the extracellular proteome of pathogenic-phase Histoplasma capsulatum. J Proteome Res 2011, 10(4):1929-1943.

56. Youseff BH, Holbrook ED, Smolnycki KA, Rappleye CA: Extracellular superoxide dismutase protects histoplasma yeast cells from host-derived oxidative stress. PLoS Pathog 2012, 8(5):e1002713.

57. Semighini CP, Harris SD: Regulation of apical dominance in Aspergillus nidulans hyphae by reactive oxygen species. Genetics 2008, 179(4):1919-1932.

58. Scott B, Eaton $\mathrm{CJ}$ : Role of reactive oxygen species in fungal cellular differentiations. Curr Opin Microbiol 2008, 11(6):488-493.

59. Krishnan A, Almen MS, Fredriksson R, Schioth HB: The origin of GPCRs: identification of mammalian like Rhodopsin, adhesion, glutamate and frizzled GPCRs in fungi. PLoS One 2012, 7(1):e29817.

60. Gladfelter AS: Guides to the final frontier of the cytoskeleton: septins in the filamentous fungi. Curr Opin Microbiol 2010, 13(6):720-726.

61. Bowman $\mathrm{BH}$, White TJ, Taylor JW: Human pathogeneic fungi and their close nonpathogenic relatives. Mol Phylogenet Evol 1996, 6(1):89-96.

62. Marion CL, Rappleye CA, Engle JT, Goldman WE: An alpha-(1,4)-amylase is essential for alpha-(1,3)-glucan production and virulence in Histoplasma capsulatum. Mol Microbiol 2006, 62(4):970-983. Epub 2006 Oct 13.

63. Viriyakosol S, Fierer J, Brown GD, Kirkland TN: Innate immunity to the pathogenic fungus Coccidioides posadasii is dependent on TLR2 and dectin-1. Infect Immun 2005, 73(3).

64. Webster RH, Sil A: Conserved factors Ryp2 and Ryp3 control cell morphology and infectious spore formation in the fungal pathogen Histoplasma capsulatum. Proc Natl Acad Sci USA 2008, 105(38):14573-14578.

65. Nemecek JC, Wuthrich M, Klein BS: Global control of dimorphism and virulence in fungi. Science 2006, 312(5773):583-588.

66. Nunes LR, Costa De Oliveira R, Leite DB, Da Silva VS, Dos Reis Marques E, Da Silva Ferreira ME, Ribeiro DC, De Souza Bernardes LA, Goldman MH, Puccia R, et al: Transcriptome analysis of Paracoccidioides brasiliensis cells undergoing mycelium-to-yeast transition. Eukaryot Cell 2005, 4(12):2115-2128.

67. Monteiro JP, Clemons KV, Mirels LF, Coller JA Jr, Wu TD, Shankar J, Lopes $C R$, Stevens DA: Genomic DNA microarray comparison of gene expression patterns in Paracoccidioides brasiliensis mycelia and yeasts in vitro. Microbiology 2009, 155(Pt 8):2795-2808.

68. Moran GR: 4-Hydroxyphenylpyruvate dioxygenase. Arch Biochem Biophys 2005, 433(1):117-128.

\section{doi:10.1186/1471-2180-13-121}

Cite this article as: Viriyakosol et al:: Gene expression in human fungal pathogen Coccidioides immitis changes as arthroconidia differentiate into spherules and mature. BMC Microbiology 2013 13:121. 